\title{
Insight into the sensing mechanism of an impedance based electronic tongue for honey botanic origin discrimination
}

\author{
Youssef Elamine $^{\mathrm{a}, \mathrm{b}}$, Pedro M.C. Inácio ${ }^{\mathrm{b}, \mathrm{c}}$, Badiâa Lyoussi ${ }^{\mathrm{a}}$, Ofélia Anjos ${ }^{\mathrm{d}, \mathrm{e}, \mathrm{f}}$, Leticia M. Estevinhoo ${ }^{g}$, \\ Maria da Graça Miguel $^{\mathrm{b}}$, Henrique L. Gomes ${ }^{\mathrm{b}, \mathrm{c}, *}$ \\ ${ }^{a}$ Laboratory of Physiology-Pharmacology-Environmental Health, Faculty of Sciences Dhar El Mehraz, BP 1796 Atlas, University Sidi Mohamed Ben Abdallah, Fez 30 000, \\ Morocco \\ ${ }^{\mathrm{b}}$ Universidade do Algarve, Faculdade de Ciências e Tecnologia, 8005-139 Faro, Portugal \\ ${ }^{\mathrm{c}}$ Instituto de Telecomunicações, Avenida Rovisco, Pais 1, 1049-001 Lisboa, Portugal \\ d Instituto Politécnico de Castelo Branco, Castelo Branco 6001-909, Portugal

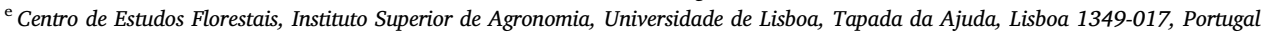 \\ ${ }^{\mathrm{f}}$ Centro de Biotecnologia de Plantas da Beira Interior, Castelo Branco 6001-909, Portugal \\ ${ }^{\mathrm{g}}$ Centro de Investigação de Montanha (CIMO), Instituto Politécnico de Bragança, 5300-252 Bragança, Portugal
}

\section{A R T I C L E I N F O}

\section{Keywords:}

Electronic tongue

Small signal impedance

Electrical-double-layer

Honey

\begin{abstract}
A B S T R A C T
An impedance based electronic tongue was developed and used to discriminate honey of different botanic origin. The e-tongue presented here is based on the small-signal frequency response of the electrical double-layer established between the honey solution and an array of four different sensing units composed by gold, carbon, indium-tin-oxide, and doped silicon. The ability of the e-tongue to discriminate honey of different floral origins was demonstrated by distinguishing honey from Bupleurum and Lavandula pollen prevalence. The honey fingerprint obtained with the e-tongue was validated by parallel melissopalenogical analysis and physico-chemical methods. It is demonstrated that the e-tongue is very sensitive to changes on the honey electrical conductivity. Small differences in electrical conductivity are introduced by the presence of ionisable organic acids and mineral salts. Moreover, we propose that the sensitivity of the tongue to changes in electrical conductivity can be explored to probe other complex liquid substances.
\end{abstract}

\section{Introduction}

Electronic tongue (e-tongue) technology is gaining attention from the scientific community as a method that can be applied in various fields, mainly to evaluate quality and authenticity of food products [1-5]. Over the last few years there have been extensive examples of sensitive, fast responding e-tongues for the classification and a certification of several types of beverages [3,6], olive oil [7], honey and coffee $[8,9]$ and pollutants in water $[3,4,10]$. Detection of adulteration and counterfeiting of products is also being reported [4,11-15].

The e-tongue instrumentation is formed by an array of sensing units that can be composed by lipid membranes, ion-selective electrodes, conducting polymers or noble metals $[3,16,17]$. Because the identification of samples is most of the time a classification task, there has been a trend to use artificial intelligence and information visualization methods to enhance the performance of e-tongues [18]. Recent advances of e-tongues can be found in several reviews $[4,16,17,19,20]$.
Several measuring methodologies can be used to address the sensing elements in e-tongue system. The most-used employed are electrochemical measurements, namely, potentiometry, amperometry and cyclic voltammetry. In 2002 Riul et al. [21] introduced the use of smallsignal impedance measurements in electronic tongues. Low-signal impedance measurements offer the advantage of using materials composing the sensing units do not need to be electroactive and there is no need of a reference electrode. Impedance based e-tongues or impedimetric tongues are based on measuring the small-signal impedance of the electrical double-layer (EDL) or Helmholtz layer established at the electrode/electrolyte interface over a frequency range [22,23].

Honey is an attractive substance to be evaluated by e-tongues. The honey floral origin has a strong impact on the commercial value, thus the floral determination and certification play an important role in quality control. European legislation specifies that the commercialization of honey must made reference to the origin, whether blossom or plant (Codex Alimentarius Commission, 1970; Council Directive 74/

\footnotetext{
* Corresponding author at: Universidade do Algarve, Faculdade de Ciências e Tecnologia, 8005-139 Faro, Portugal.

E-mail address: hgomes@ualg.pt (H.L. Gomes).
} 
409/EEC, 1974). Honey floral origin and honey adulteration are difficult to detect without performing laboratory analysis. Until now the most reliable method that can confirm honey botanic origin is known as melissopalynogical analysis. This method basically counts the pollen species present in the honey. This is an expensive laboratorial analysis that requires trained people with scientific knowledge for visual identification of pollen species [24]. This method tends to be viewed as a reference tool in scientific research rather than the method of identifying the types of honey as merchandise. Other alternative methods for honey botanic origin characterization involve: the determination of the volatile fraction by gas chromatography-mass spectrometry [25,26], mineral content [27], physicochemical parameters such as analysis of phenolic compounds [28,29], or phenolic profiling using liquid chromatography-tandem mass spectrometry [30-34]. These methods require rigorous sample preparation and expensive instrumentation. Because of this, the European Community is encouraging the development of harmonized analytical methods to verify the compliance with the quality specifications for different types of honeys. An e-tongue fulfils the requirements of a fast, inexpensive and a reliable tool to confirm that a particular sample belongs to a specific floral origin. It can be implemented in a portable hand instrument used in the field. Furthermore an e-tongue will be an important asset to help the commercialization chain, to screen for counterfeiting and adulteration of honey.

Several studies reported the use of e-tongues to characterize honey. Wei et al. [35] used a commercial available potentiometric e-tongue (aAstree from Alpha MOS company, France), to classify honey of different floral and geographical origins. In other study the same group reported the use of a voltammetry electronic tongue to classify monofloral honeys of seven kinds of floral origins [36]. Dias et al. [37] reported on the use of an array with 20 all-solid-state potentiometric electrodes with polymeric membranes, to discriminate commercial honeys with different pollen profiles. A potentiometric e-tongue was also used as a tool to distinguish honey in three different states: raw, liquefied and pasteurize [38].

In addition to the use of e-tongues some authors use a combination of different measuring methods to probe honey. Chirantan et al. [39] used impedance spectroscopy complemented with optical methods as a tool for quantification of adulteration in different floral species of honey. Ulloa et al. [23] compared the performance of optical measurements with an electronic tongue and a study by Graziella et al. [22] demonstrated that impedance spectroscopy alone, also can be used to determine honey floral origin.

Despite the success of numerous studies on the use of e-tongues to probe honey, none of the above studies provides clear insight into the electrochemistry behind the ability of the tongues to discriminate the floral origin of honey samples.

It is also important to note, that although, the reported e-tongues use different measuring methods it is evident that all reported tongues share a common detecting mechanism. This mechanism relies on the establishment of an EDL or Helmholtz layer at the interface between a sensing electrode and the honey solution. The Helmholtz layer is the critical sensing layer in all the e-tongues reported for honey. Minute perturbations in this interfacial polarized layer can be probed by measuring the potential at the electrode (potentiometric measurements), by using voltage ramps (voltammetry) or by using small alternate signals (impedance spectroscopy).

This paper starts by presenting the individual characterization of the sensor units forming the electronic tongue. The stability and reproducibility of each sensing electrode is presented in detail. The ability of each electrode to discriminate different samples is then presented. While some materials such as gold, perform well, others such as doped $n$-type silicon have a low ability to discriminate the floral origin of honey samples. The e-tongue fingerprint was confirmed and validated by mellissopalenogical analysis in combination with standardized physico-chemical characterization involving the sugar content, the electrical conductivity, and the light absorbance. Finally, the discussion section highlights the major advantages of implementing a portable etongue instrument.

\section{Material and methods}

\subsection{Honey samples}

Eighteen samples of Bupleurum floral origin from Morocco were purchased in the summer of 2015 directly from beekeepers and from Taza and Fez beekeeper associations. This honey type was described for the first time by Elamine et al. [40] Thirty one honey samples with lavender floral origin were purchased from beekeepers from different regions in Portugal. The samples were stored in glass containers and kept under dark ambient conditions.

Electrical conductivity, moisture content, color, glucose and fructose contents were determined according to the procedures described in literature [41]. The quantitative analysis of pollen spectrum in honey samples was performed according to the International Commission for Bee Botany (ICBB), as previously described [24]. For the e-tongue measurements, honey samples were diluted in Millipore water.

\subsection{Experimental set-up and statistics}

Fig. 1(a) shows a photograph of the e-tongue and Fig. 1(b) shows a schematic diagram of the spatial arrangement of the sensing electrodes. The plastic vessel has a capacity of $15 \mathrm{ml}$. Measurements were carried out using $10 \mathrm{ml}$ of a honey solution. Small-signal impedance measurements were carried out by an impedance analyzer, a Fluke PM 6306. Both the capacitance $\left(C_{P}\right)$ and resistance $\left(R_{P}\right)$ were individually measured as function of frequency between each sensing electrode and a common counter electrode. The amplitude of the ac signal was $50 \mathrm{mV}$. Each honey sample is characterized by 8 impedance spectra. Each spectra measures 49 different frequencies from $60 \mathrm{~Hz}$ up to $1 \mathrm{MHz}$. A honey sample is then characterized by a total of 392 experimental data points. Principal Component Analysis (PCA) [42] was used to process the impedance data.

The e-tongue was formed by a set of four distinct sensing electrodes made of conducting materials. As conducting materials, we use (i) thermal evaporated thin film of gold on a glass slide, (ii) a carbon film, (iii) a glass slide coated with an Indium-Tin-Oxide (ITO) layer and (iv) a highly doped $n$-type silicon wafer $\left(n^{+}\right.$-Si). A platinum grid was used as a common electrode. The carbon thin film electrodes are screen-printed on top of Valox and they are manufactured by Gwent Group Ltd (ref: BE2150327D2/001).

ANOVA statistical test was used for comparing the means of the used parameters and for the estimation of the significance level. The difference is considered significant when $\mathrm{p}<0.05$.

The PCA analysis and dendograms were carried out using Matlab scripts.

\section{Results and discussion}

The sensing mechanism of an impedimetric tongue relies on measuring the impedance of the electrical double-layer (EDL) established at the electrode/honey solution interface. It is then important to demonstrate that our frequency observation window $(60 \mathrm{~Hz}$ to $1 \mathrm{MHz}$ ) probes the EDL impedance and not only the honey bulk solution.

Fig. 2(a) shows for the gold/honey solution/platinum electrode interface the frequency dependence of the capacitance $\left(C_{P}\right)$ and the loss $\left(G_{P}=1 /\left(\omega R_{P}\right)\right.$ where $\omega$ is the angular frequency. Fig. 2(b) shows the same impedance data but now represented as loss tangent $(\tan \delta$ ), which is given by $\tan \delta=G_{P} /\left(C_{P}\right)$. The $\tan \delta$ curve shows a MaxwellWagner relaxation at approximately $30 \mathrm{kHz}$. A Maxwell-Wagner relaxation is expected when the system being measured behaves as two different layers in series. From a physical point of view, the two layers in series are formed by the EDL in series with the bulk electrolyte layer. 
(a)

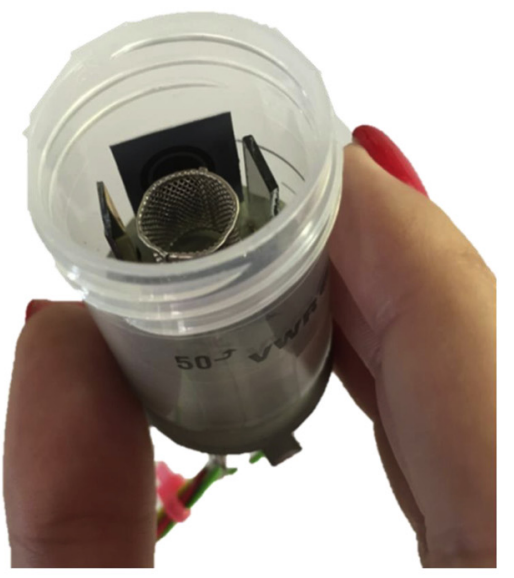

(b)

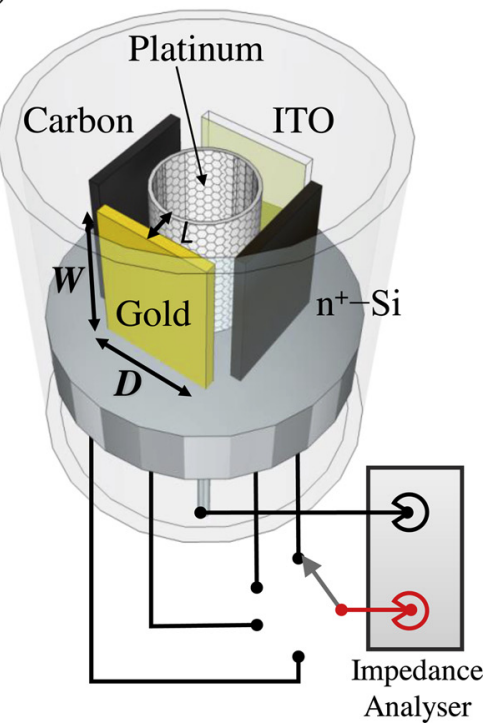

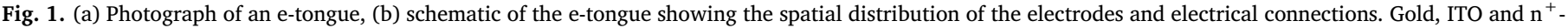
silicon electrodes have an individual active area of $1 \mathrm{~cm}^{2}$. The carbon electrode has an area of $0.39 \mathrm{~cm}^{2}$.

These two layers have very different impedances. The EDL has a significant higher capacitance. As the frequency increases, there is a transition from the high capacitive layer (interface) to the lower capacitive layer (bulk electrolyte). The relaxation is known as MaxwellWagner relaxation and gives rise to a peak in $\tan \delta$ curve as function of the frequency as shown in Fig. 2(b).
The above discussion can be proper understood with the help of equivalent circuits. From an electrical point of view, an EDL behaves as a capacitor. Therefore, the electrode in contact with the honey solution is modelled as a capacitor in parallel with a resistor. Since the electrodes are made of different materials, two different EDLs layers are established, one at the sensing and other at the counter electrode (a)

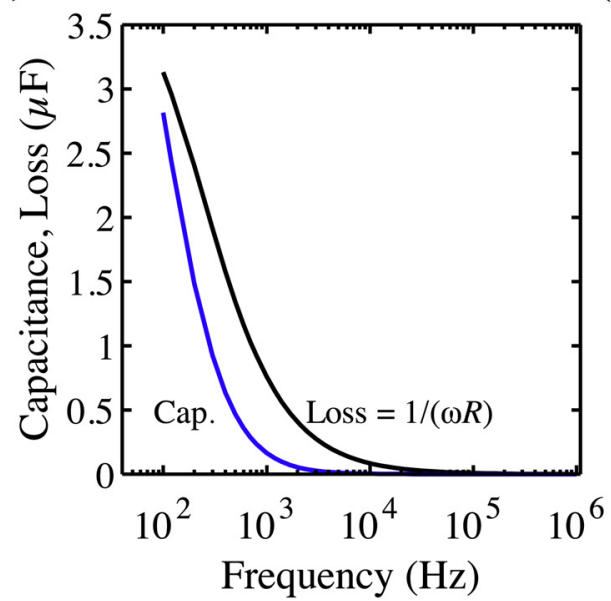

(b)

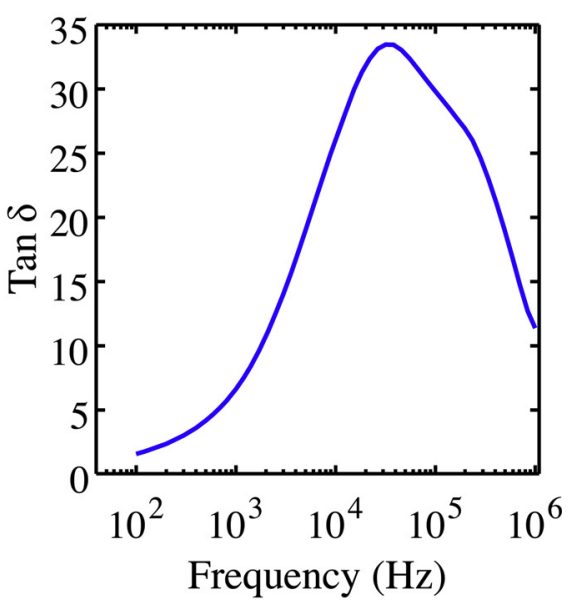

(c)

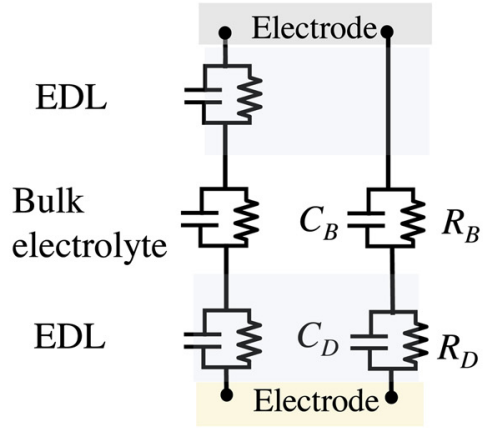

(E1)

(E2)

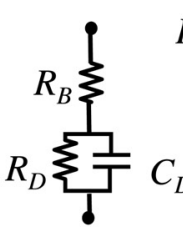

(E3)

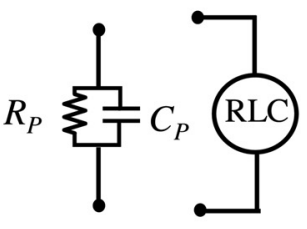

$C_{D}$

(E4)

Fig. 2. Frequency dependence of the gold/honey/platinum impedance. (a) Frequency dependence of the capacitance $\left(C_{P}\right)$ and loss $=1 /\left(\omega R_{P}\right)$. $(b)$ Frequency dependence of the $\tan \delta$ (c) Equivalent circuit description of the electrodes immersed into the honey solution. 
(a)

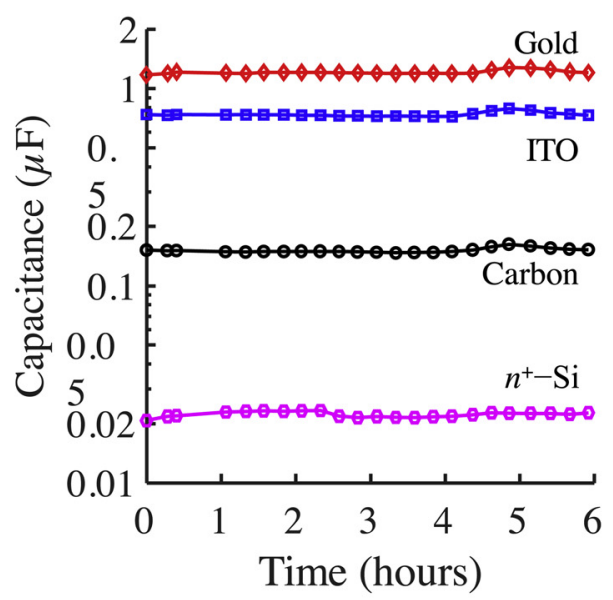

(b)

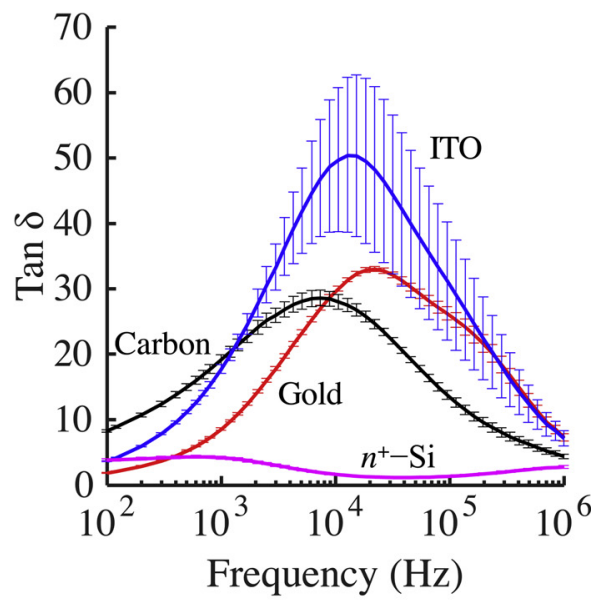

(c)

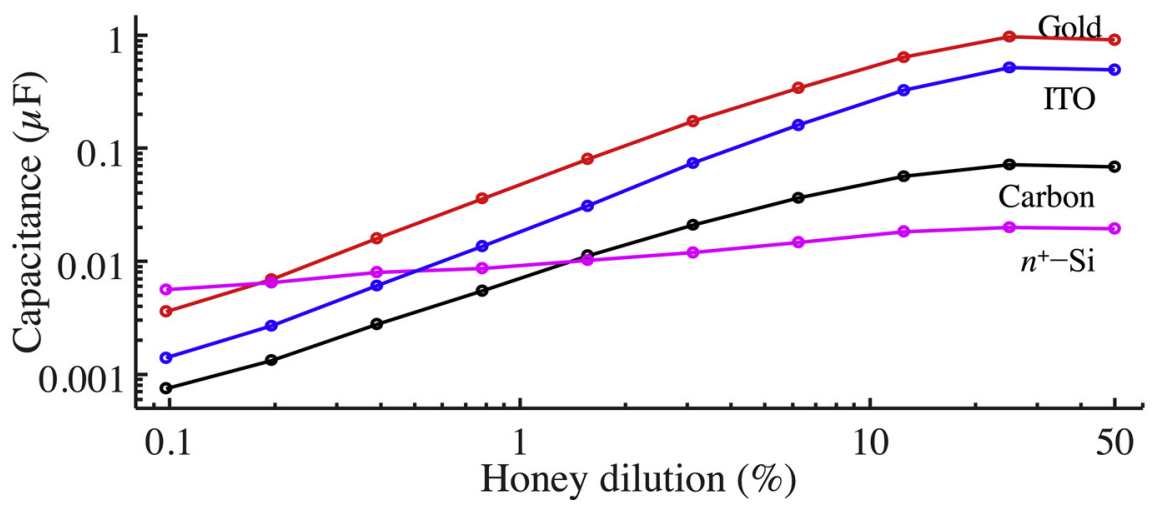

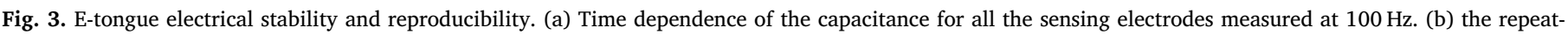
ability assay for all the sensors. Results are expressed as $\tan \delta \pm$ standard deviation. (c) $\mathrm{C}_{\mathrm{P}}$ dependence on the honey dilution factor.

(platinum) as shown in Fig. 2(c) (circuit E1). Comparatively to the bulk electrolyte layer the two EDLs have higher impedance. Although, the two EDLs are different, for the sake of simplicity, the layers can be combined in a single equivalent circuit (circuit E2). The circuit E2 combines two EDLs layers by a $C_{D}$ in parallel with $R_{D}$. The interfacial capacitance $C_{D}$ models the extent to which the electrode is polarizable, and $R_{D}$ takes into account the presence of Faradic currents. Faradic currents result from oxidation/reduction reactions occurring at the electrode/electrolyte interface. These reactions cause the transduction of charge carriers from electrons in the metal electrode to ions in the electrolyte. As it will be shown later the low frequency value for $R_{D}$ is very high and the amplitude of the testing signals is only $50 \mathrm{mV}$. Therefore, Faradic currents are very small and can be neglected. The parallel network $\left(R_{\mathrm{D}} / / C_{D}\right)$ of the double-layer appears in series with a honey solution resistance $\left(R_{B}\right)$ and capacitance $\left(C_{B}\right)$. The equivalent circuit described above and schematically represented in Fig. 2(c) circuit (E2) allows us to understand the frequency response of the electrode/honey interface.

Because the distance $(d)$ between sensing and counter electrode is relatively large $(d=5 \mathrm{~mm}) C_{B}$ is very small and can be neglected. The overall system can then be described the equivalent circuit E3 on Fig. 2(c). The circuit E3 is a reduction of the more complex model. In reality the interfacial capacitance is not a pure electrical capacitance. The capacitive element $C_{D}$ is more accurately described as a Constant Phase Element (CPE) [43]. A complete equivalent model of the electrode/electrolyte interface should include the so-called "Warburg" diffusion element. A popular example is the Randles circuit [44]. The Randles circuit can simulate the low frequency dispersion on the impedance. However, the impact of the diffusion or constant phase elements on the data analysis carried out here is relatively small. For the sake of simplicity these elements are not included in the circuit model of Fig. 2. The circuit E3 represents the overall equivalent parallel resistance $\left(R_{P}\right)$ and capacitance $\left(C_{P}\right)$ measured externally using an impedance analyser or by a RCL meter. by

The equivalent admittance $Y_{T}$ of the series-parallel network is given

$Y_{T}=\frac{1}{R_{P}}+j \omega C_{P}$

Where $R_{P}$ and $C_{P}$ are the total parallel resistance and capacitance, respectively, given by

$C_{P}(\omega)=\frac{R_{D}^{2} C_{D}+R_{B}^{2} C_{B}+\omega^{2} R_{D}^{2} R_{B}^{2} C_{D} C_{B}\left(C_{D}+C_{B}\right)}{\left(R_{D}+R_{B}\right)^{2}+\omega^{2} R_{D}^{2} R_{B}^{2}\left(C_{D}+C_{B}\right)^{2}}$

$R_{P}(\omega)=\frac{\left(R_{D}+R_{B}\right)^{2}+\omega^{2} R_{D}^{2} R_{B}^{2}\left(C_{D}+C_{B}\right)^{2}}{R_{D}+R_{B}+\omega^{2} R_{B} R_{D}\left(R_{D} C_{D}^{2}+R_{B} C_{D}^{2}\right)}$

This circuit exhibits dispersion in capacitance centered around a relaxation frequency, $f_{r}$, given by

$f_{r}=\frac{1 / R_{B}+1 / R_{D}}{2 \pi\left(C_{B}+C_{D}\right)}$

Which for $R_{D}>>R_{B}$ reduces to

$f_{r}=\frac{1}{2 \pi R_{B}\left(C_{B}+C_{D}\right)}$

The resistance $R_{B}$ controls $f_{r}$. This frequency depends on the electrolyte conductivity but also on the separation between electrodes and 
sensing area. According to Fig. 2(b) the relaxation frequency is higher than $10 \mathrm{kHz}$. Therefore, it is demonstrated that the e-tongue is proper designed to record the Maxwell-Wagner relaxation and also to probe the impedance of the sensing electrode/honey interface, which dominates the impedance for frequencies lower than $f_{r}$.

Prior to use as an e-tongue instrument, the reproducibility and repeatability of the impedance of each electrode was evaluated. In order to inspect for impedance drifts as function of time, measurements were performed for periods as long as $6 \mathrm{~h}$. This time is significant longer that the time required to perform a full impedance characterization of a honey solution, which is less than $1 \mathrm{~min}$. Fig. 3(a) shows that for all electrodes the capacitance remains constant for a six hours long period. To inspect for reproducibility, 10 measurements were carried out using the same honey sample in a repeated fashion. Between measurements, the tongue was washed with ultrapure water and dried. The error bars in Fig. 3(b) show the impedance variations for each electrode. The data is represented as $\tan \delta$. This impedance parameter is defined as $C_{P} /$ $\left(\omega G_{P}\right)$. The ITO sensor showed the lowest reproducibility with a standard deviation of $50.43 \pm 11.83(23.5 \%)$ in the peak of $\tan \delta$ curve. The gold electrode is the sensor with the highest reproducible behaviour with a standard deviation of $33.01 \pm 0.37$ (1.1\%).

The optimization of the e-tongue requires also the optimization of the honey dilution factor. 10 honey dilutions were prepared in ultrapure water, starting from $0.1 \%$ up to $50 \%$ of dilution. Fig. 3(c) shows how the honey dilution affects the EDL capacitance measured at a test frequency of $100 \mathrm{~Hz}$. The capacitance rises as a power law of the dilution factor until it saturates at a dilution factor of approximately $40 \%$. A dilution factor of $50 \%$ (in the saturation plateau) in water was selected to perform the impedance measurements.

In the following sections the e-tongue is used to characterize different samples of honey. The goal is to demonstrate the ability of the tongue to discriminate honey of different floral origin. The characterization was performed using the frequency dependence of the impedance. First the performance of each individual sensing electrode was evaluated. Fig. 4 shows the PCA using the $\tan \delta$ data as function of frequency for each individual sensing electrode. In contrast to other etongue methodologies in which each sensor provides only one single value (potentiometry), impedance measurements provide an $m * n$ matrix for each sensor. Here $m$ corresponds to the $\tan \delta$ values at different frequencies, and $n$ to the number of honey samples. The number of frequency points (49) is equal to the number of honey samples.

The black squares represent the Zandaz honey samples which have a Bupleurum pollen prevalence. The filled blue circles represent the samples of honey with lavender pollen prevalence. In addition, the plots in Fig. 4 also shown 4 odd samples that although have been purchased as lavender type (empty blue circles) or Zandaz honey type (empty black squares) their melissopalynological analysis did not show a prevalence of corresponding pollen species. In spite of that, physicochemical methods confirm these odd samples indeed belong to their floral origin. These samples remain in the border of their corresponding cluster.

In addition to the experimental data extracted from the frequency response of $\tan \delta$, Fig. 4 (a) also shows a distribution of how $\tan \delta$ values at specific frequencies correlate the obtained principal components. The pink lines in Fig. 4 show this correlation. The projection of a pink line end point on the $\mathrm{XX}$ axis is the relevance of $\tan \delta$ value by the first principal component (PC1). In other words, the higher is a coordinate value on a given axis, more relevant is its relevance by the corresponding principal component, and more important is its role in discriminating honey samples. The signal frequency used to measure $\tan \delta$ is an implicit parameter represented by the arrow in Fig. 4. The pattern created by the pink lines is different for each electrode and this pattern reflects the ability of each electrode to discriminate different varieties of honey.

Two distinct clusters of data distribute along two well-separated curves, the blue circles follow a curve starting near the axis of the PC1 and bending upwards into the second quadrant (Fig. 4(a)). These data points correspond to the lavender honey samples with normal electrical conductivity. Honey from Zandaz is represented by the black squares. The sample distribution also follows a curve starting near the origin but extending into the first quadrant. The two curves almost mix with each other over a small region, represented by the blue shadow area. Zandaz honey samples have a high $\tan \delta$ value at high frequencies, which explain their location in the positive part of the PC1.

Fig. 4(b) shows the PCA analysis of the $\tan \delta$ data for the doped silicon $\left(n^{+}-\mathrm{Si}\right)$ sensor. This sensor has the lowest interfacial capacitance $(0.02 \mu \mathrm{F}$ at $100 \mathrm{~Hz})$. The first component (PC1) explained $77 \%$ and PC2 $10 \%$ of the given data. In contrast, to the gold sensor, the $n^{+}$-Si sensor shows sparsely distributed data points in all the quadrants of the PCA plot. This is particular visible for the samples with lavender floral origin. The cluster from Zandaz honey samples aggregates into a narrow region located in the fourth quadrant. The shadow blue region includes the odd samples with lavender floral origin. Although, the $n^{+}$. Si sensor shows a broad distribution, particular for the honey with lavender origin, there is no mixing between the two clusters in the PCA plot. Samples from Zandaz cluster into a narrow region in the fourth quadrant of the PCA plot.

The performance of the Indium Tin Oxide (ITO) sensing electrode is demonstrated in the plot (c) of Fig. 4. The two varieties of honey are now organized into two well-separated clusters in distinct quadrants. Honey with lavender floral origin is mostly located in the first quadrant while the honey with Bupleurum pollen prevalence is clustering in the second quadrant. The shadow blue regions show again the location of the 4 odd samples with lavender origin. The odd samples are now mixed into the Zandaz cluster.

Fig. 4(d) shows the ability of the carbon electrode to discriminate the two types of honey. The honey samples are distributed into two clusters resemble to the distribution provided by the ITO electrode, however, in comparison with the ITO, the data points are more spread. The ability of the carbon electrode to discriminate honey with different origins is relatively poor. In a similar way as the ITO electrode the carbon electrode wrongly classifies the 4 odd lavender floral origin as samples with Bupleurum pollen prevalence.

In summary, the above analysis reveals that different electrodes have different ability to discriminate honey with different floral origin. The gold sensing electrode shows the highest ability to discriminate the two varieties of honey. The gold electrode organizes the data into two well-defined curves that diverge from the centre of the PCA plot into opposite directions. Comparatively to the gold electrode the data obtained by the ITO electrode is spread over the 4 quadrants but still organized into two well-separated clusters. The carbon and the $n^{+}-\mathrm{Si}$ electrodes have the lowest ability to discriminate honey samples.

Since, the e-tongue has four sensing electrodes, we may use the entire set of data from all the electrodes to construct PCA plots. Fig. 5(a) shows the PCA plot constructed using the $\tan \delta$ data from the 4 sensing electrodes. The discrimination of the two types of honey is now remarkably clear. The two varieties of honey distributed along two welldefined lines in distinct quadrants.

Fig. 5(b) shows the PCA plot using the individual resistance $\left(R_{P}\right)$ and the capacitance $\left(C_{P}\right)$ impedance parameters. Comparatively to the $\tan \delta$ data, the samples are still organized into two distinct clusters but spread over the PCA plot.

In order to evaluate how the electronic tongue performs in respect with other conventional physicochemical methods. The honey samples were also characterized by, (i) light absorbance, (ii) water content, (iii) glucose and fructose contents and (iv) by electrical conductivity measurements. The higher is the honey conductivity the higher the mineral content $[17,26]$. Light absorbance at several wavelengths was used to quantify melanoidins, phenolic and flavonoid contents [28]. It is important to state that the use of physicochemical raw data does not provide a good discrimination between honey samples and the data must also be processed using PCA analysis. Fig. 5(c) shows a PCA biplot 

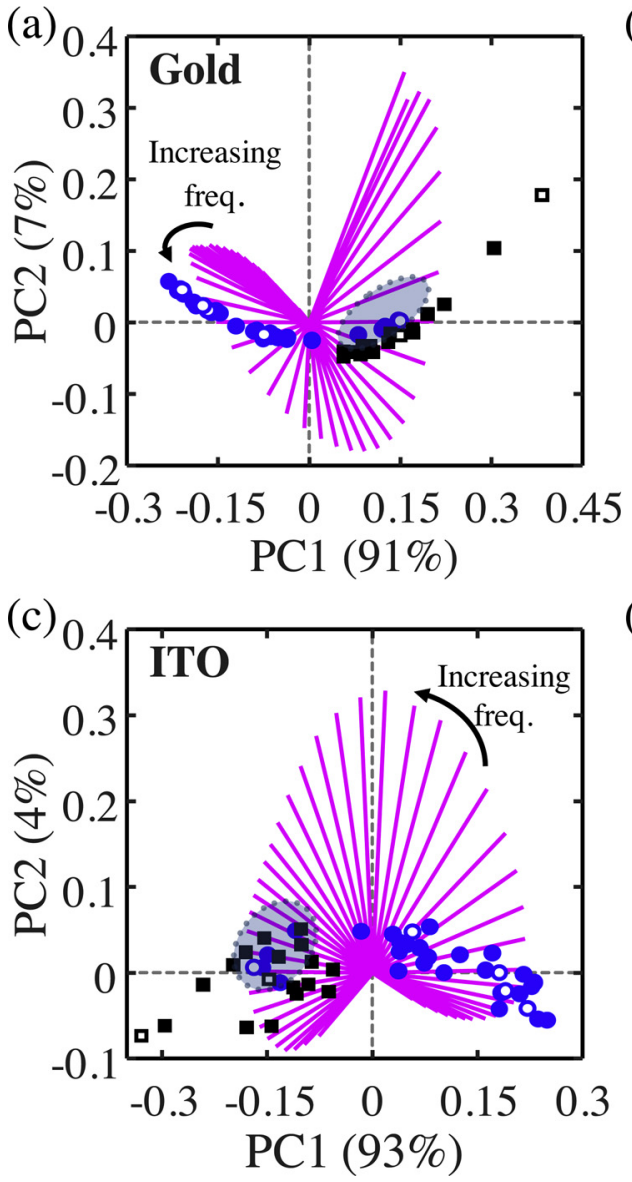

(b)

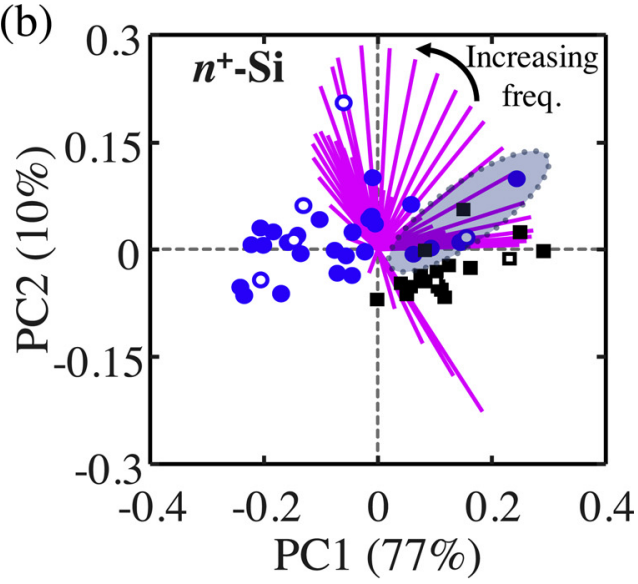

(d)

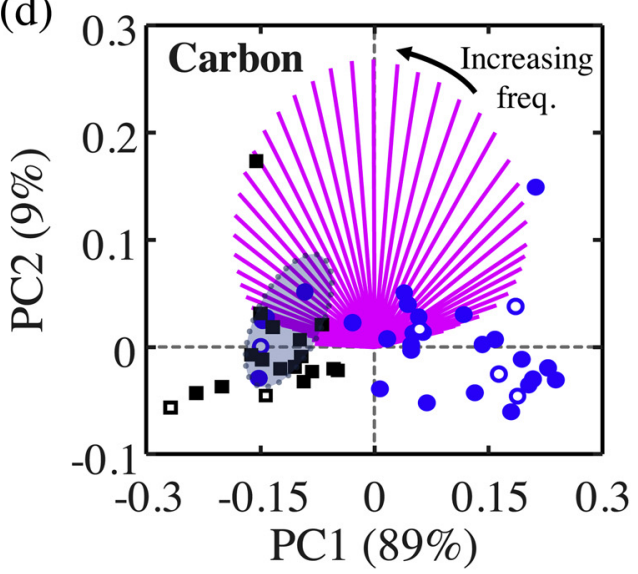

Fig. 4. PCA discrimination patterns for etongue. (a) Gold sensor. (b) $\mathrm{n}^{+}-\mathrm{Si}$ sensor. (c) ITO sensor. (d) Carbon sensor. Blue circles represent samples with lavender pollen prevalence; black squares samples with Bupleurum pollen prevalence. Empty black squares and empty blue circles represent odd samples purchased, as belonging to a specific floral origin but this origin was not confirmed using melissopalynology (For interpretation of the references to colour in this figure legend, the reader is referred to the web version of this article). of honey samples using normalized physicochemical parameters mentioned above. The red lines show the relationship between the physicochemical parameters with the principal components. The PC1 and the PC2 explained $60 \%$ and $17 \%$, of the given data respectively, and correlated the electrical conductivity, the absorbance values in the first case and glucose, fructose and water contents in the second case. Honey samples with Bupleurum pollen prevalence (black squares) are discriminated from samples with lavender floral origin (blue circles) by the first component, correlating positively the electrical conductivity and the absorbance values.

Glucose, fructose and water contents showed little effect in discriminating the honey types (see Fig. 5(c)), but enable to distinguish subgroups in each floral origin. Samples from both botanical origins with similarity in terms of glucose content have tendency to occupy the positive part of the second principal component, while those with fructose abundance occupied the negative part. Samples located in the red shadow region of the PCA plot have lavender floral origin. However, these samples are also characterized by an unusual high conductivity and color intensity compared to the remaining lavender samples. The PCA analysis classified them in a middle region between the two botanical honey types.

Fig. 5(d) shows the PCA biplot of the data integrating both the information of the physicochemical characterization and the melissopalenological analysis. The studied parameters/variables are shown in red lines. Only the important ones are labelled by their names. The first two components explained a sum of $98 \%$ of the given data, and correlated in the first component electrical conductivity as a major parameter. The second component correlated the major influencing pollen species, mainly Lavandula and Bupleurum spinosum, and allowed the discrimination between the samples of the different floral origins. The integration of the information provided by both characterization tools, makes the isolation of the odd lavender honey samples (samples in the red shadow region) clearer.

Honey from a specific floral origin does not have $100 \%$ of pollen from single specie but the overall composition has a percentage of other pollen species. It is known that depending of the percentage and composition of these secondary pollen species is possible to divide the honey into subgroups with different composition. These sub-groups with a specific dominant floral origin area not revealed by the PCA analysis. The identification of these subgroups is done by hierarchical clustering. A cluster tree known as dendrogram is used to represent data. The dendrogram looks for the correlation between samples and identifies sets of samples (subgroups) that are similar. Fig. 6 shows two dendrograms for the honey samples studied. The dendrogram have been made using the PCA analysis of the e-tongue data. The samples are arranged along the bottom of the dendrogram and referred to as honey sample numbers. The vertical axis is labelled distance $(D)$ and measures the dissimilarity between honey samples. Highly similar subgroups are nearer the bottom of the dendrogram.

Fig. 6(a) shows a dendrogram based on the data of the first two principal components of the e-tongue data of Fig. 5(a). The dendrogram reveals three main sub-groups within the Lavandula honey group. These sub-groups are identified as $\mathrm{L}_{1}, \mathrm{~L}_{2}$ and $\mathrm{L}_{3}$. Similar analysis was carried out for Bupleurum based honey. Again, three different subgroups named $B_{1}, B_{2}$ and $B_{3}$ are distinguished. These subgroups are shown in Fig. 6(b). The use of a dendrogram analysis of the e-tongue data shows that it is possible to identify subgroups within the main floral group.

It is now important to understand what the differences between subgroups are. This identification requires a detailed physicochemical analysis of the samples belonging to each subgroup. Table 1 presents the physicochemical parameters of each subgroup. All subgroups have almost identical sugar and water contents. However, they have marked 

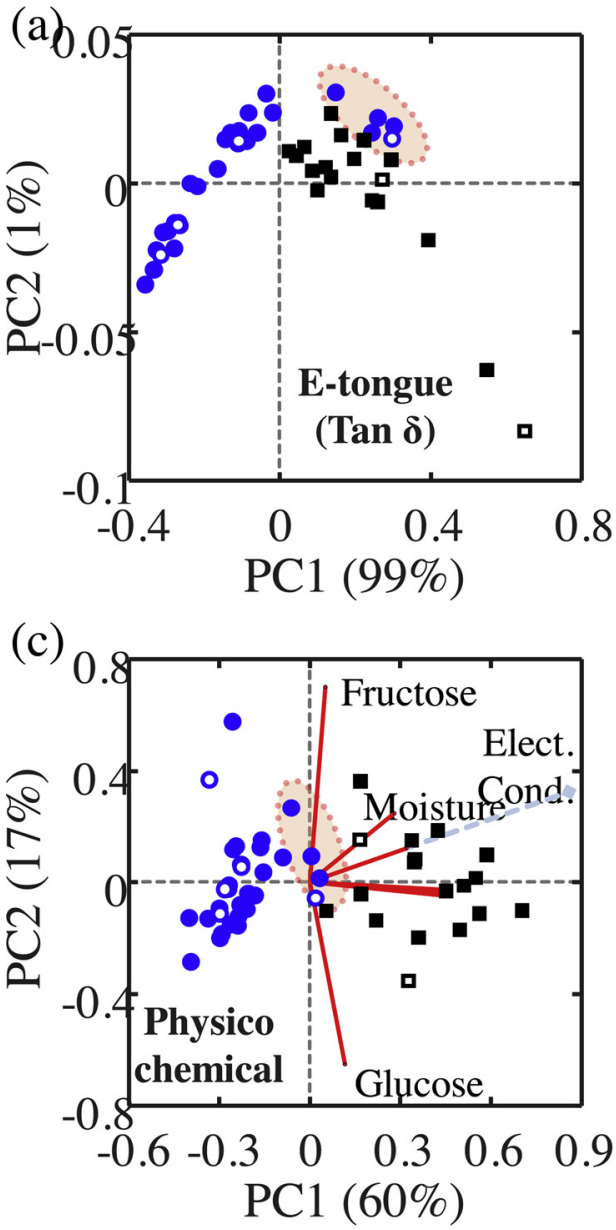

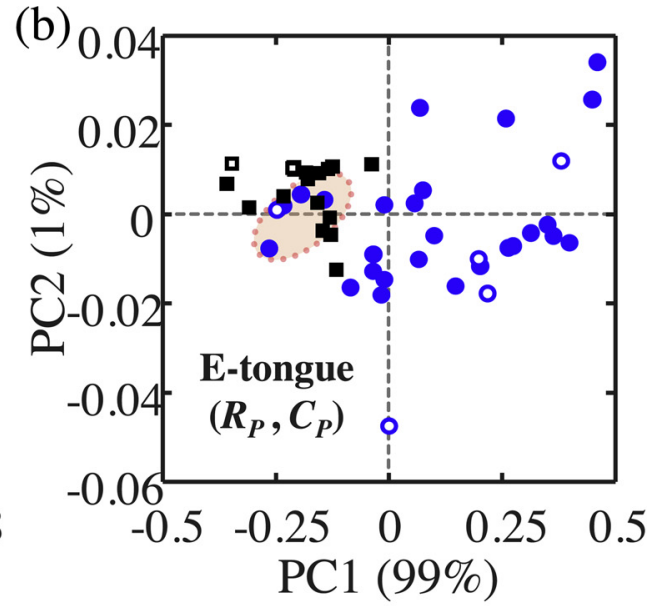

(d)

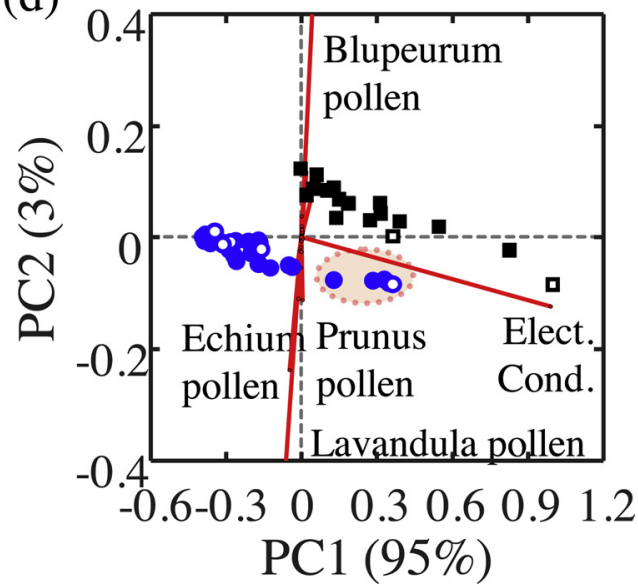

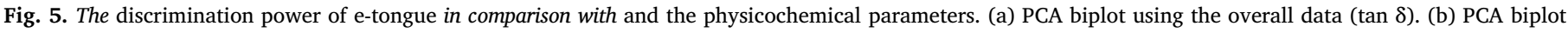

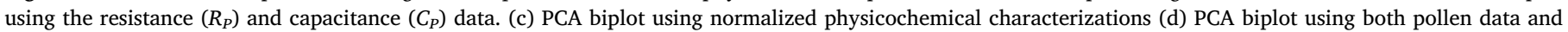

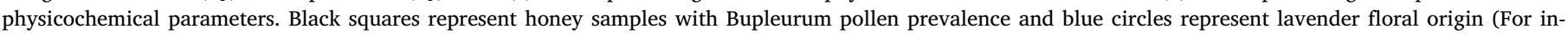
terpretation of the references to colour in this figure legend, the reader is referred to the web version of this article).

differences on the electrical conductivity and colour. Fig. 7 shows histograms for colour and electrical conductivity. The sub-group $L_{1}$ has the lowest electrical conductivity and the lighter colour, the subgroup $\mathrm{L}_{3}$ has the highest electrical conductivity and colour intensity. $\mathrm{L}_{2}$ has values of conductivity and colour between the other two subgroups. Similar behaviour is showed for the Bupleurum based honey, the subgroups $\mathrm{B}_{1}, \mathrm{~B}_{2}$ and $\mathrm{B}_{3}$ are also characterized by differences on electrical conductivity and colour.

A comparison between the histogram for Bupleurum and Lavandula based honey also shows that while in lavender type of honey colour increases with honey conductivity, the opposite behaviour is observed for the Bupleurum based honey. In this case the higher the electrical conductivity more transparent becomes the Bupleurum based honey. Although colour and conductivity seems to be somehow linked, this relation depends on the type of secondary species contribution to the main honey composition. Further studies are required to elucidate this interesting relation between honey colour and electrical conductivity.

The physical chemical analysis reveals that the e-tongue is able to distinguish not only the floral origin of the honey, but furthermore, the tongue is also sensitive to changes in the electrical conductivity. Fig. 7(a) shows that the e-tongue can distinguish differences in electrical conductivity of $100 \mu \mathrm{S} / \mathrm{cm}$ and differences in colour of $8 \mathrm{~mm}$ Pfund. The real discrimination sensitivity may even be lower. Further studies with samples with more similar values for conductivity and colour are required to evaluate the discrimination threshold of the impedimetric e-tongue.
Table 1 also shows that the sub-groups within each type of honey do not show differences in terms of moisture, glucose, and fructose contents. Therefore, we may conclude that within a specific floral origin of honey, the sugar and water contents remain unchanged. The changes occur in the electrical conductivity which according to the literature is caused by the contribution of other botanical species $[45,46]$. This shed light why the e-tongue has a quite powerful discriminating power. The impedimetric tongue relies on the electrical properties of the electrical double-layer. The interfacial impedance of the EDL is strongly dependent on the electrical conductivity of the electrolyte solution. The interfacial capacitance and resistance vary dramatically upon changes on the electrolyte solution. In our study the changes in electrical conductivity amongst subgroups of the same honey are introduced by the presence of secondary botanical species. By detecting minute changes on the electrical conductivity, the e-tongue is able to distinguish variations matching the changes in the pollen composition.

The e-tongue ability to probe honey was evaluated with honey samples with identical sugar contents but with very different colour and pollen composition. Differences in electrical conductivity are somehow related with the colour and pollen composition as reported previously by other authors [45]. This relationship makes electrical conductivity a useful parameter for discriminating honeys of different floral origin [47]. It is also known that the acidity of any honey is directly related to its floral sources. Honey contains a number of different acids, including about 18 aminoacids, many different organic acids, as well as aliphatic and aromatic acids. The aromatic acids greatly contribute to the flavour 

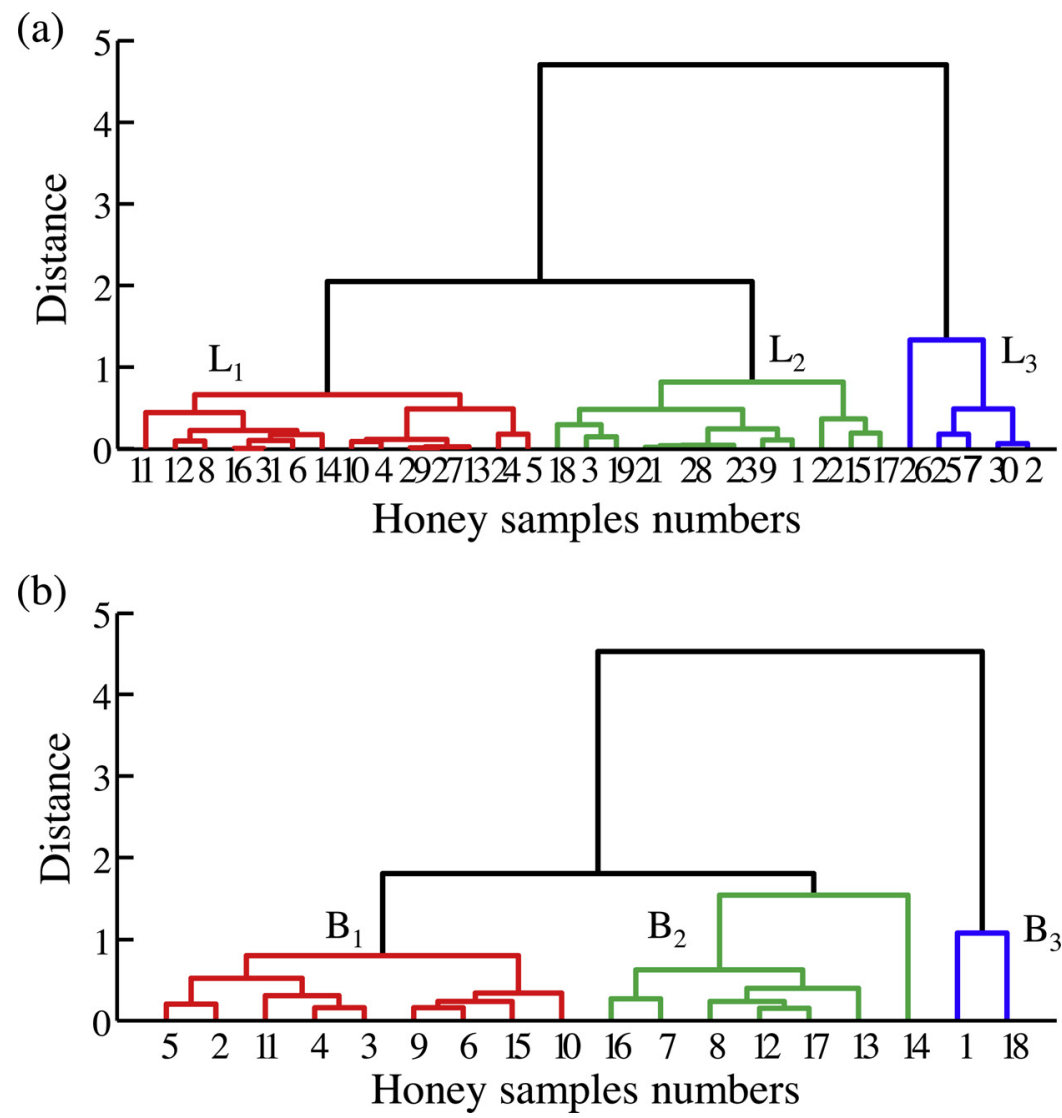

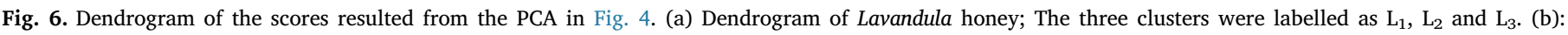
Dendrogram of Bupleurum honey; The three obtained clusters were labelled as $\mathrm{B}_{1}, \mathrm{~B}_{2}$ and $\mathrm{B}_{3}$.

of honey [5]. Honey electrical conductivity is strongly related with the acidity and it has been reported that natural acidity of honeys may increase with the storage duration, especially when extracted from combs with propolis or when honey deteriorates due to fermentation [48]. Moreover, honey adulteration with sugar syrup lower its acidity while a honey sample adulterated with inverted sugar present a higher acidity [49]. Since the tongue developed and presented here is highly sensitive to ionisable species it should also be able to detect honey adulteration and ageing.

The e-tongue relies on the use of 4 different sensing electrodes. However, the performance comparison between the different electrodes shows that the use of gold electrode alone has the required discrimination ability and does not lower the overall e-tongue performance. The use of expensive platinum electrode can be discharged in future e-tongue implementations. All sensing electrodes were selected on terms of stability and reusability after proper washing with water.

\section{Conclusions}

An impedimetric electronic tongue was developed and successful applied to discriminate honeys with different floral origin. The tongue can distinguish Bupleurum and Lavender based honeys with almost identical sugar and moisture contents.

The sensing unit is comprised of 4 different bare electrodes (not functionalized). A comparison between the different sensing electrodes tested, reveals that the best ability to discriminate honey is achieved by the electrode with the highest interfacial capacitance per unit area, the gold electrode. However, the combined use of the four sensing electrodes provides the highest discriminating power. The e-tongue stability, reliability and reusability were also demonstrated.

The use of dendrograms complemented with physico-chemical analysis provides clear insight into the sensing mechanism. The etongue is essentially sensitive to changes in the honey electrical conductivity. Differences in electrical conductivity between samples with different floral origin are brought-in by the presence of ionisable

Table 1

Melissopalenological, and physico-chemical characterization of the honey samples. Results are presented as Mean \pm SD.

\begin{tabular}{|c|c|c|c|c|c|c|}
\hline \multirow[b]{2}{*}{ Subgroup } & \multicolumn{3}{|c|}{ Honey from Lavandula floral origin } & \multicolumn{3}{|c|}{ Honey from Bupleurum floral origin } \\
\hline & $\mathrm{L}_{1}$ & $\mathrm{~L}_{2}$ & $\mathrm{~L}_{3}$ & $\mathrm{~B}_{1}$ & $\mathrm{~B}_{2}$ & $\mathrm{~B}_{3}$ \\
\hline Lavandula pollen (\%) & $37.76 \pm 8.39$ & $42.41 \pm 18.79$ & $31.71 \pm 11.55$ & & & \\
\hline Bupleurum pollen (\%) & & & & $58.18 \pm 14.63$ & $46.64 \pm 12.67$ & $34.13 \pm 15.16$ \\
\hline Electrical conductivity $(\mu \mathrm{S} / \mathrm{cm})$ & $186.76 \pm 23.35$ & $278.22 \pm 33.15$ & $522.48 \pm 45.53$ & $405.11 \pm 33.65$ & $540.71 \pm 56.70$ & $853.16 \pm 47.16$ \\
\hline Colour (mm Pfund) & $25.28 \pm 7.12$ & $39.91 \pm 15.97 b$ & $73.28 \pm 15.71$ & $63.10 \pm 21.72$ & $51.75 \pm 15.63$ & $44.67 \pm 22.09$ \\
\hline Moisture content (\%) & $18.36 \pm 0.67$ & $18.88 \pm 0.49$ & $18.76 \pm 0.50$ & $19.73 \pm 0.60$ & $19.58 \pm 1.03$ & $19.05 \pm 0.35$ \\
\hline Glucose (\%) & $24.03 \pm 4.53$ & $22.80 \pm 1.82$ & $24.64 \pm 2.49$ & $24.04 \pm 1.87$ & $25.28 \pm 3.65$ & $23.24 \pm 0.07$ \\
\hline Fructose (\%) & $36.14 \pm 2.86$ & $35.57 \pm 1.95$ & $34.99 \pm 2.99$ & $38.00 \pm 2.17$ & $37.47 \pm 2.46$ & $34.72 \pm 1.20$ \\
\hline
\end{tabular}




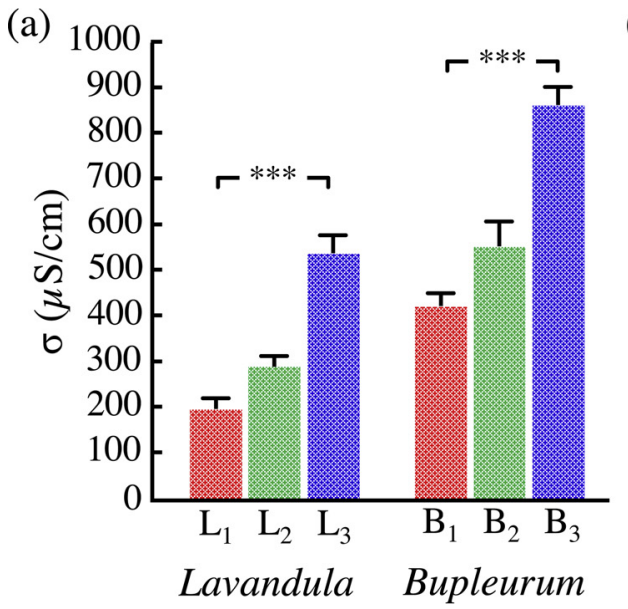

(b)

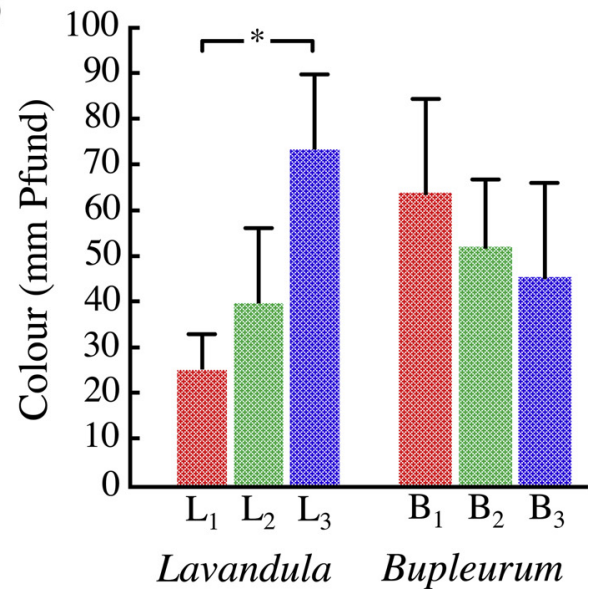

Fig. 7. Electrical conductivity and colour of the two honey subgroups $\mathrm{L}_{1}, \mathrm{~L}_{2}$ and $\mathrm{L}_{3}$ (Fig. 6 (a)) for Lavandula honey and $\mathrm{B}_{1}, \mathrm{~B}_{2}$ and $\mathrm{B}_{3}$ for Bupleurum honey (Fig. 6 (b)). (a) electrical conductivity and (b) colour for the two groups. The values are plotted as mean $\pm \mathrm{SD}$, difference was accepted to be significant with a $\alpha=0.05 .{ }^{*} \mathrm{p}<0.05 ; * * * \mathrm{p}<0.001$. organic acids and mineral salts.

Comparatively, to conventional conductivity measurements relying in bulk measurements, the e-tongue is extremely sensitive to minute changes on the electrical conductivity. The ultra-high sensitivity to ionisable substances occurs because the tongue probes the low-frequency impedance variations occurring in an ultra-thin interfacial polarizable electrode/electrolyte interface (Helmholtz layer).

The e-tongue configuration and the measuring methodology proposed here may be applied to a variety of other complex liquids where changes in ionisable species occur.

\section{Acknowledgments}

We gratefully acknowledge financial support from the Portuguese Foundation for Science and Technology (FCT), the Instituto de Telecomunicações (UID/Multi/04326/2013), the Centro para os recursos biologicos e alimentos mediterranicos (UID/BIA/04325/2013) and the Centro de Estudos Florestais (UID/AGR/00239/2013).

\section{References}

[1] H. Smyth, D. Cozzolino, Instrumental methods (Spectroscopy, Electronic Nose, and Tongue) as tools to predict taste and aroma in beverages: advantages and limitations, Chem. Rev. 113 (2013) 1429-1440, https://doi.org/10.1021/cr300076c.

[2] P.D. Patel, (Bio)sensors for measurement of analytes implicated in food safety: a review, TrAC - Trends Anal. Chem. 21 (2002) 96-115, https://doi.org/10.1016/ S0165-9936(01)00136-4.

[3] C.M. Daikuzono, C.A.R. Dantas, D. Volpati, C.J.L. Constantino, M.H.O. Piazzetta, A.L. Gobbi, D.M. Taylor, O.N. Oliveira, A. Riul, Microfluidic electronic tongue, Sens. Actuators B Chem. 207 (2015) 1129-1135, https://doi.org/10.1016/j.snb.2014.09. 112.

[4] Y. Vlasov, A. Legin, A. Rudnitskaya, A. D’Amico, C. Di Natale, «Electronic tongue» - new analytical tool for liquid analysis on the basis of non-specific sensors and methods of pattern recognition, Sens. Actuators B Chem. 65 (2000) 235-236, https://doi.org/10.1016/S0925-4005(99)00323-8.

[5] F. Winquist, P. Wide, I. Lundström, An electronic tongue based on voltammetry, Anal. Chim. Acta 357 (1997) 21-31, https://doi.org/10.1016/S0003-2670(97) 00498-4.

[6] A. Riul, H.C. De Sousa, R.R. Malmegrim, D.S. Dos Santos, A.C.P.L.F. Carvalho, F.J. Fonseca, O.N. Oliveira, L.H.C. Mattoso, Wine classification by taste sensors made from ultra-thin films and using neural networks, Sens. Actuators, B Chem. 98 (2004) 77-82, https://doi.org/10.1016/j.snb.2003.09.025.

[7] L.G. Dias, N. Rodrigues, A.C.A. Veloso, J.A. Pereira, Monovarietal extra - virgin olive oil classification : a fusion of human sensory attributes and an electronic tongue, Eur. Food Res. Technol. 242 (2016) 259-270, https://doi.org/10.1007/ s00217-015-2537-4.

[8] A.M.S. Costa, M.M.C. Sobral, I. Delgadillo, A. Rudnitskaya, Electronic tongue as a rapid tool for the assessment of coffee flavour and chemical composition, IEEE SENSORS 2014 Proc. (2014) 2126-2129, https://doi.org/10.1109/ICSENS.2014. 6985458.

[9] E.J. Ferreira, R.C.T. Pereira, A.C.B. Delbem, O.N.O Jr, L.H.C. Mattoso, Random Subspace Method for Analysing Coffee With Electronic Tongue vol. 43, (2007), pp. 5-7, https://doi.org/10.1049/el.

[10] F. Winquist, J. Olsson, M. Eriksson, Multicomponent analysis of drinking water by a voltammetric electronic tongue, Anal. Chim. Acta 683 (2011) 192-197, https://doi. org/10.1016/j.aca.2010.10.027.

[11] La. Dias, A.M. Peres, M. Vilas-Boas, Ma. Rocha, L. Estevinho, Aa S.C. Machado, An electronic tongue for honey classification, Microchim. Acta 163 (2008) 97-102, https://doi.org/10.1007/s00604-007-0923-8.

[12] M. Peres, M. Vilas-boas, M.A. Rocha, A. Dias, A.S.C. Machado, Original Paper an Electronic Tongue for Honey Classification, (2008), https://doi.org/10.1007/ s00604-007-0923-8.

[13] K. Tiwari, B. Tudu, R. Bandyopadhyay, A. Chatterjee, Identification of monofloral honey using voltammetric electronic tongue, J. Food Eng. 117 (2013) 205-210, https://doi.org/10.1016/j.jfoodeng.2013.02.023.

[14] G. Pioggia, F. Di Francesco, A. Marchetti, M. Ferro, A. Ahluwalia, A composite sensor array impedentiometric electronic tongue. Part I. Characterization, Biosens. Bioelectron. 22 (2007) 2618-2623, https://doi.org/10.1016/j.bios.2006.10.031.

[15] C. Das, S. Chakraborty, K. Acharya, N. Kumar, Talanta FT-MIR supported Electrical Impedance Spectroscopy based study of sugar adulterated honeys from di ff erent $\mathrm{fl}$ oral origin, Talanta 171 (2017) 327-334, https://doi.org/10.1016/j.talanta.2017. 05.016.

[16] A. Riul, C.A.R. Dantas, C.M. Miyazaki, O.N. Oliveira, Recent advances in electronic tongues, Analyst 135 (2010) 2481-2495, https://doi.org/10.1039/c0an00292e.

[17] L. Escuder-Gilabert, M. Peris, Review: highlights in recent applications of electronic tongues in food analysis, Anal. Chim. Acta 665 (2010) 15-25, https://doi.org/10. 1016/j.aca.2010.03.017.

[18] C. Krantz-Rülcker, M. Stenberg, F. Winquist, I. Lundström, Electronic tongues for environmental monitoring based on sensor arrays and pattern recognition: a review, Anal. Chim. Acta 426 (2001) 217-226, https://doi.org/10.1016/S00032670(00)00873-4.

[19] D. Ha, Q. Sun, K. Su, H. Wan, H. Li, N. Xu, F. Sun, L. Zhuang, N. Hu, P. Wang, Recent achievements in electronic tongue and bioelectronic tongue as taste sensors, Sens. Actuators B Chem. 207 (2015) 1136-1146, https://doi.org/10.1016/j.snb.2014.09. 077.

[20] F. Winquist, Voltammetric electronic tongues - basic principles and applications, Microchim. Acta 163 (2008) 3-10, https://doi.org/10.1007/s00604-007-0929-2.

[21] A. Riul, D.S. Dos Santos, K. Wohnrath, R. Di Tommazo, A.C.P.L.F. Carvalho, F.J. Fonseca, O.N. Oliveira, D.M. Taylor, L.H.C. Mattoso, Artificial taste sensor: efficient combination of sensors made from Langmuir-Blodgett films of conducting polymers and a ruthenium complex and self-assembled films of an azobenzenecontaining polymer, Langmuir 18 (2002) 239-245, https://doi.org/10.1021/ la011017d.

[22] G. Scandurra, G. Tripodi, A. Verzera, Impedance spectroscopy for rapid determination of honey floral origin, J. Food Eng. 119 (2013) 738-743, https://doi.org/10. 1016/j.jfoodeng.2013.06.042.

[23] P.A. Ulloa, R. Guerra, A.M. Cavaco, A.M. Rosa da Costa, A.C. Figueira, A.F. Brigas, Determination of the botanical origin of honey by sensor fusion of impedance etongue and optical spectroscopy, Comput. Electron. Agric. 94 (2013) 1-11, https:// doi.org/10.1016/j.compag.2013.03.001.

[24] J. Louveaux, A. Maurizio, G. Vorwohl, Methods of melissopalynology, Bee World 5 (1978) 139-153, https://doi.org/10.1080/0005772X.1978.11097714.

[25] V. Kaškonienè, P.R. Venskutonis, V. Čeksterytè, Composition of volatile compounds of honey of various floral origin and beebread collected in Lithuania, Food Chem. 111 (2008) 988-997, https://doi.org/10.1016/j.foodchem.2008.05.021.

[26] E. Alissandrakis, Pa. Tarantilis, P.C. Harizanis, M. Polissiou, Aroma investigation of unifloral Greek citrus honey using solid-phase microextraction coupled to gas chromatographic-mass spectrometric analysis, Food Chem. 100 (2007) 396-404, https://doi.org/10.1016/j.foodchem.2005.09.015.

[27] S. Bogdanov, M. Haldimann, W. Luginbühl, P. Gallmann, Minerals in honey: environmental, geographical and botanical aspects, J. Apic. Res. 46 (2007) 269-275, https://doi.org/10.3896/IBRA.1.46.4.11.

[28] I.K. Karabagias, A.V. Badeka, S. Kontakos, S. Karabournioti, M.G. Kontominas, Botanical discrimination of Greek unifloral honeys with physico-chemical and chemometric analyses, Food Chem. 165 (2014) 181-190, https://doi.org/10.1016/ j.foodchem.2014.05.033.

[29] I.K. Karabagias, M.V. Vavoura, C. Nikolaou, A.V. Badeka, S. Kontakos, 
M.G. Kontominas, Floral authentication of Greek unifloral honeys based on the combination of phenolic compounds, physicochemical parameters and chemometrics, Food Res. Int. 62 (2014) 753-760, https://doi.org/10.1016/j.foodres. 2014.04.015.

[30] I. Sergiel, P. Pohl, M. Biesaga, Characterisation of honeys according to their content of phenolic compounds using high performance liquid chromatography/tandem mass spectrometry, Food Chem. 145 (2014) 404-408, https://doi.org/10.1016/j. foodchem.2013.08.068.

31] V. Kaškonienè, P.R. Venskutonis, Floral markers in honey of various botanical and geographic origins: a review, Compr. Rev. Food Sci. Food Saf. 9 (2010) 620-634, https://doi.org/10.1111/j.1541-4337.2010.00130.x.

[32] E. Anklam, A review of the analytical methods to determine the geographical and botanical origin of honey, Food Chem. 63 (1998) 549-562, https://doi.org/10. 1016/S0308-8146(98)00057-0.

[33] J.S. Amaral, M.B.P.P. Oliveira, I. Mafra, A Comprehensive Review on the Main Honey Authentication Issues: Production and Origin, 00 (2017), https://doi.org/10. 1111/1541-4337.12278.

[34] L. PERSANO ODDO, R. PIRO, Main European unifloral honeys: descriptive sheets, Apidologie 35 (2004) 38-81, https://doi.org/10.1051/apido:2004049.

[35] Z. Wei, J. Wang, W. Liao, Technique potential for classification of honey by elec tronic tongue, J. Food Eng. 94 (2009) 260-266, https://doi.org/10.1016/j jfoodeng.2009.03.016.

[36] Z. Wei, J. Wang, Classification of monofloral honeys by voltammetric electronic tongue with chemometrics method, Electrochim. Acta 56 (2011) 4907-4915, https://doi.org/10.1016/j.electacta.2011.02.065.

[37] L.A. Dias, A.M. Peres, M. Vilas-Boas, M.A. Rocha, L. Estevinho, A.A.S.C. Machado, An electronic tongue for honey classification, Microchim. Acta 163 (2008) 97-102, https://doi.org/10.1007/s00604-007-0923-8.

[38] I. Escriche, M. Kadar, E. Domenech, L. Gil-Sánchez, A potentiometric electronic tongue for the discrimination of honey according to the botanical origin. Comparison with traditional methodologies: physicochemical parameters and volatile profile, J. Food Eng. 109 (2012) 449-456, https://doi.org/10.1016/j. jfoodeng.2011.10.036.

[39] C. Das, S. Chakraborty, K. Acharya, N.K. Bera, D. Chattopadhyay, A. Karmakar, S. Chattopadhyay, FT-MIR supported Electrical Impedance Spectroscopy based study of sugar adulterated honeys from different floral origin, Talanta 171 (2017) 327-334, https://doi.org/10.1016/j.talanta.2017.05.016.

[40] Y. Elamine, S. Aazza, B. Lyoussi, M. Dulce Antunes, L.M. Estevinho, O. Anjos, M. Resende, M.L. Faleiro, M.G. Miguel, Preliminary characterization of a Moroccan honey with a predominance of Bupleurum spinosum pollen, J. Apic. Res. 57 (2018), https://doi.org/10.1080/00218839.2016.1265759.

[41] S. Bogdanov, Harmonised Methods of the International Honey Commission, Swis Bee Research Centre, Bern, Swtitzerland, 2002.

[42] L. Bertacchini, M. Cocchi, M. Li Vigni, A. Marchetti, E. Salvatore, S. Sighinolfi, M. Silvestri, C. Durante, The Impact of Chemometrics on Food Traceability, 1st ed., Copyright (C) 2013 Elsevier B.V. All rights reserved, 2013, https://doi.org/10.1016/ B978-0-444-59528-7.00010-7.

[43] K.S. Cole, R.H. Cole, Dispersion and absorption in dielectrics I. Alternating current characteristics, J. Chem. Phys. 9 (1941) 341-351, https://doi.org/10.1063/1 1750906.

44] K.W. Somerton, Kinetics of Rapid Electrode Reactions vol.2, (1952), pp. 937-950.

[45] O. Anjos, C. Iglesias, F. Peres, J. Martínez, Á. García, J. Taboada, Neural networks applied to discriminate botanical origin of honeys, Food Chem. 175 (2015) 128-136, https://doi.org/10.1016/j.foodchem.2014.11.121.

[46] A. Terrab, a.G. González, M.J. Díez, F.J. Heredia, Mineral content and electrical conductivity of the honeys produced in Northwest Morocco and their contribution to the characterisation of unifloral honeys, J. Sci. Food Agric. 83 (2003) 637-643, https://doi.org/10.1002/jsfa.1341.

[47] M.T. Sancho, S. Muniategui, M.P. Sánchez, J.F. Huidobro, J. Simal, Relationships between electrical conductivity and total and sulphated ash contents in Basque honeys, Apidologie 22 (1991) 487-494, https://doi.org/10.1051/apido:19910501. [48] J. Pourtallier, Y. Taliercio, Honey control analyses, Apiacta. (1972) 2-5.

[49] D. Yadata, Detection of the Electrical Conductivity and Acidity of Honey from Different Areas of Tepi vol. 2, (2014), pp. 59-63.

Youssef Elamine concluded a Master degree in Biological Sciences and Health and he is currently working in a $\mathrm{PhD}$ degree project for the characterization and biological activities of monofloral honey at the University of FSDM, Fez, Morocco. He is doing a short stay in the Organic Electronics research laboratory at the University of the Algarve.

Pedro M. C. Inácio received his master's degree in University of the Algarve in 2013, and is currently working towards the $\mathrm{PhD}$ degree in the Organic Electronics Research Group at the University of Algarve, Faro, Portugal. His main research interests are focused on the electrical characterization of organic and bioelectronic devices.

Lyoussi Badiâa is professor at the University Sidi Mohamed Ben Abdallah, Fez, Morocco. She received Doctorat degree in Physiology and pharmacology from University of Montpellier, France in 1984 and a second $\mathrm{PhD}$ degree in of pharmacology from the University of UCL, Belgium in 1992. She has over 30 years experience in the physiopathology and pharmacology of natural products from medicinal plants. Her publication record includes more than 90 scientific journal papers, and chapters in books on the area of plants used in traditional medicine, ethnopharmacology and management of several pathologies. She is the head of Physiology-Pharmacology and Environmental Health Laboratory, member of scientific committee of Association Francophone of Apitherapy and member of the Apitherapy Commission of Apimondia.

Ofélia Anjos is professor at the Agrarian School of Polytechnique Institute of Castelo Branco. She completed his PhD studies in Materials Science in 2002 at the Instituto Superior Técnico from the University of Lisbon. Ofélia Anjos is author of several papers in reputed journals, wrote some book chapters and presented more 100 oral communications. Concerning their more recent research activity, she work with spectroscopic techniques, namely FTIR-ATR, NIR and RAMAN applied to forest and food products.

Leticia M. Estevinho received the Zootechnical Engineering degree (summa cum laude) in 1985 and the MSc degree in biotechnology (with merit) in 1989. In 1995, she concluded the PhD degree in science, given by Minho University, Braga, Portugal. She has published more than 120 articles in indexed international journals and has written severa book chapters. She is an expert on microbiology, chemistry, and toxicology. Since 1986 she is the Head of the Microbiology Laboratory at the Polytechnic Institute of Braganca Portugal. She is chief editor of 3 Journals and is part of the editorial staff of 17 Journal. Estevinho serves as a Coordinator Professor with Agregação (habilitation) in the Polytechnic Institute of Braganca, Braganca, Portugal.

Maria da Graça Miguel is professor at Universidade do Algarve teaching Pharmacognosy and Phytotherapy. She completed her PhD at Universidade do Algarve. The subject of her research has been bioactive compounds of plant and honey origin, particularly with antioxidant and anti-inflammatory activities for application as biofilms in fruits and vegetables.

Henrique L. Gomes received the $\mathrm{PhD}$ degree from the University College of North Wales, Bangor, U.K., in 1994. He is currently an Associate Professor with the Electronics Engineering Department, University of the Algarve, Faro, Portugal. His research interest have been directed towards the electrical characterisation of electronic devices such as field effect transistors, diodes and capacitor structures. He has a recognized experience in small signal impedance measurements techniques. Since 2000, his research activities have expanded to encompass the interaction between electronic devices and living cells to develop biosensors and biomedical devices. 